\title{
MAESTRO CONDENADO, DISCÍPULO INDIGNADO. LA IMAGEN DE PEDRO ABELARDO Y LA EXASPERADA DEFENSA DE BERENGARIO DE POITIERS
}

\author{
NATALIA JAKUBECKI ${ }^{1}$ \\ A David E. Luscombe (1938-2021)
}

RESUMEN: Como es sabido, Pedro Abelardo, el más célebre maestro del siglo XII, supo provocar la ira no solo de sus colegas laicos, sino también la de influyentes representantes de la Iglesia. Así lo confirman los dos concilios en los que fue condenado, Soissons (1121) y Sens (1141). Desde finales del siglo XIX, mucho se ha escrito tanto acerca de los acontecimientos fácticos como sobre los rencores, envidias y hasta confabulaciones homicidas perpetradas contra el Palatino. Si a este panorama conflictivo se le suma la escasa reproducción de sus obras en los años posteriores a su muerte, y las prácticamente nulas menciones explícitas que otros autores medievales han hecho de su filosofía, podría dar la impresión de que su figura y sus ideas son hoy mucho mejor apreciadas de lo que fueron realmente en su propia época. Sin embargo, no es así. Contamos con numerosas declaraciones que acreditan la relevancia de Abelardo en el universo escolar del siglo XII. No es casual, pues, que incluso en nuestros días los especialistas se sigan refiriendo a él como el Magister por antonomasia.

Así, el presente escrito se encuentra dedicado a las pasiones que Abelardo, en su calidad de maestro, despertó entre sus discípulos. Se compone de dos grandes momentos: el primero consta de un breve repaso por cuatro testimonios particularmente sugestivos sobre su trayectoria escolar; el segundo se centra en un "indignado alumno", Berengario de Poitiers, y su Apologia Berengarii Pictauensis contra sanctum Bernardum Claraeuallensem abbatem et alios qui condemnauerunt Petrum Abaelardum.

Palabras clave: Pedro Abelardo - Berengario de Poitiers - Apologia - Sens.

\footnotetext{
${ }^{1}$ UBA - Conicet - Usal. E-mail: natalia.jakubecki@ filo.uba.ar Fecha de recepción: 5/10/2021, fecha de aceptación: 9/12/2021. DOI: https://doi.org/10.46553/sty.30.30.2021.p255-272
}

Stylos. 2021; 30 (30); pp. 255-272; ISSN: 0327-8859; E-ISSN: 2683-7900 
ABSTRACT: It is well known that Peter Abelard, the most famous master of the $12^{\text {th }}$ century, knew how to drive mad not only his laic colleagues of urban schools, but also important ecclesiastical leaders. This is confirmed by the two Councils in which Abelard was condemned: Soissons (1121), and Sens (1141). Since the end of the $19^{\text {th }}$ century, rivers of ink have flowed concerning both factual events and grudges, envies, and even the murder conspiracies perpetrated against Abelard. If to this troubling scenario is added the very little reproduction of their works in the years after his death, and the lack of explicit mentions of Abelard's doctrine done by other medieval authors, it might seem that his image and his ideas are today much better appreciated than they really were in his own time. Nevertheless, it is not the case. We have lots of statements proving Abelard's reputation in the scholar life of the $12^{\text {th }}$ century. It is not casual that even nowadays medievalists keep referring to him as the Magister par excellence.

Then, this paper is dedicated to the passions that Abelard, as master, inflamed among his students. It is divided into two parts. The first one consists in a succinct revision of four particularly suggestive testimonies about his days as a teacher; the second part is focused on an "outraged disciple", Berenger of Poitiers, and his Apologia Berengarii Pictauensis contra sanctum Bernardum Claraeuallensem abbatem et alios qui condemnauerunt Petrum Abaelardum.

Keywords: Peter Abelard - Berengar of Poitiers - Apologia - Sens.

\section{INTRODUCCIÓN}

Como es bien sabido, Pedro Abelardo, el más célebre maestro del siglo XII, supo provocar la ira no solo de sus colegas laicos de las escuelas urbanas, sino también la de influyentes representantes de la Iglesia. Así lo confirman los dos concilios en los que fue condenado, Soissons (1121), incitado por dos de sus ex compañeros de estudio: Alberico de Reims y Lotulfo de Lombardía; y Sens (1141), impulsado principalmente por Bernardo de Claraval. Desde finales del siglo XIX, ríos de tinta han corrido tanto acerca de los

Stylos. 2021; 30 (30); pp. 255-272; ISSN: 0327-8859; E-ISSN: 2683-7900 
acontecimientos como sobre los rencores, envidias y hasta confabulaciones homicidas perpetradas contra Abelardo. Si a este panorama conflictivo se le suma la escasa reproducción de sus obras en los años posteriores a su muerte, y las prácticamente nulas menciones explícitas que otros autores medievales han hecho de su filosofía, podría dar la impresión de que su figura y sus ideas son hoy mucho mejor apreciadas de lo que fueron realmente en su propia época. Sin embargo, no es así. Contamos con numerosas declaraciones que acreditan la relevancia de Abelardo en el universo escolar del siglo XII. No es casual, pues, que incluso en nuestros días los especialistas se sigan refiriendo a él como el Magister por antonomasia.

Las siguientes páginas están dedicadas no al contenido doctrinal de la producción abelardiana, sino a las pasiones que Abelardo despertó entre sus discípulos. Entonces, luego de un repaso por algunos testimonios particularmente sugestivos, me detendré en el que Berengario de Poitiers, un ex alumno de Abelardo, nos ha legado: una invectiva dirigida primariamente contra Bernardo en la que denuncia los excesos y las torpezas que, según él, se cometieron durante el proceso de Sens; y ello por varios motivos. En primer lugar, porque es un texto poco conocido entre los estudiosos del Medioevo; ${ }^{2}$ en segundo lugar, porque aun cuando difícilmente pueda ser considerado un relato del todo fidedigno, no deja de ser una versión de lo acontecido en el concilio $;^{3}$ en tercer lugar, por su peculiar estilo literario, que bien podría caracterizarse como satírico; ${ }^{4}$ y por último, porque creo que este es-

\footnotetext{
${ }^{2}$ En octubre de 2020 Rodney Thomson y Michael Winterbottom publicaron For and Against Abelard $(F a A A)$, en el que, entre otras fuentes, se encuentran las obras de Berengario en latín e inglés. Confiamos, pues, en que este libro contribuirá con su divulgación al menos en el mundo anglófono.

${ }^{3}$ Mews (2002: 370-371), de hecho, toma en cuenta su testimonio al momento de historiar el Concilio, aunque con los debidos reparos. Curiosamente, a finales del siglo XIX, RASHDALL (1895: 55) no solo se refiere al relato de Berengario como una "well-know story", sino que incluso asegura que se la leía como representativa de los concilios del XII.

${ }^{4}$ Thomson, el editor de las obras de Berengario advirtió (1980: 91) que el texto "[...] has been completely ignored by modern studies of medieval protest and parody"; cuarenta años después, solo cambió el "completely" por "usually". Cf. THOMSON - WinTERBOTTOM (2020: xvi). De hecho, el mismo THOMPSON (1980: 100-103) ha publicado numerosos trabajos respecto del género satírico, aunque de carácter más bien general, y se dedica exclusivamente a
}

Stylos. 2021; 30 (30); pp. 255-272; ISSN: 0327-8859; E-ISSN: 2683-7900 
crito nos permite acceder, mejor que ningún otro, a la imagen que del Magister tenían sus alumnos, o al menos uno de ellos.

\section{ABELARDO, EL MAESTRO CONDENADO}

Por fortuna, y a diferencia de lo que suele suceder con la mayoría de los autores medievales, son muchos los testimonios con los que contamos acerca de la vida de Pedro Abelardo y de su entorno. En este caso, nos interesan aquellos que ayuden a darnos una idea más o menos cabal no solo del renombre, sino del fervor que los estudiantes de las nacientes escuelas urbanas sentían por él. Como no es posible analizar todos ellos, he seleccionado cuatro, que provienen de diferentes voces y, a su vez, dan cuenta de diferentes etapas de su vida. Empecemos, pues, por el principio.

Aunque el nombre de Pedro Abelardo había comenzado a propagarse por el mundillo escolar parisino ya a comienzos del siglo; más precisamente desde que, siendo un novato, había refutado con total rigurosidad la teoría sobre los universales de su maestro, Guillermo de Champeaux, ${ }^{5}$ no será sino hasta 1114, cuando le fue otorgada una cátedra en la escuela de Notre-Dame, que su prestigio se consolide. Allí, en el corazón de la Cité, enseñaría alrededor de cuatro años dialéctica y teología a la vez. Tanta fue su gloria en aquel entonces, que tiempo después, cuando la suerte comenzaba a serle esquiva, Fulco, prior del monasterio de Deuil, le recordaría en una carta precisamente esos días en los que la Europa latinófona parecía rendirse a sus pies:

"Roma te enviaba a sus estudiantes como alumnos; y la que en otro tiempo solía infundir a sus oyentes el conocimiento de todas las artes, te mostraba a sus enviados más sabio que ella, que era la sabia. [...] El

Berengario en la introducción de la primera edición de los textos. Ese mismo texto, con ligeras modificaciones, forma parte de la introducción a $F a A A$ (2020: xxii-xxv).

${ }^{5}$ La primera de las dos refutaciones tiene lugar c. 1002; la segunda, en 1108. A raíz de ello, Guillermo terminó abandonando su cátedra y recluyéndose en la abadía de San Víctor. Como observa PERNOUd (2011: 22), “durante toda su vida [Abelardo] será el importuno, el que interrumpe, argumenta, irrita y exaspera". No es de extrañar, entonces, que la lista de enemigos creciera casi a la par que la de sus admiradores.

Stylos. 2021; 30 (30); pp. 255-272; ISSN: 0327-8859; E-ISSN: 2683-7900 
terrible mar y la tempestad de las olas que se interponían no amedrentaban a la multitud de jóvenes ingleses, sino que ellos, despreciando todo peligro, acudían hacia ti una vez oído tu nombre. La remota Bretaña $\langle$ te $>$ destinaba sus bestias para que fueran educadas. Con su ferocidad domesticada, los angevinos ponían a los suyos a tu servicio. [...] Teutones y suevos se empeñaban incesantemente en exaltar, alabar y predicar tu inteligencia. Pasaré por alto a todos los habitantes de la ciudad de París, y los de las partes más cercanas y más alejadas de la Galia que de tal modo ansiaban que les enseñaras, que era como si no se pudiera encontrar conocimiento en nadie más que en ti”. 6

Otro recuerdo digno de mención es el del propio Abelardo en su Historia de mis calamidades. Un año después de su condena en Soissons, el Magister se encontraba solo, sumido en la pobreza, y urgido de recibir alumnos para poder subsistir. La noticia no tardó en esparcirse. Así, dejando atrás las comodidades urbanas, poco a poco fueron llegando al Paráclito - un precario oratorio que Pedro había levantado en Troyes- jóvenes dispuestos a pasar necesidades con tal de escuchar al maestro. Abelardo, pues, había fundado una nueva escuela, para envidia de sus detractores, quienes, según su testimonio:

"se quejaban y dolían, comentando entre sí: 'He aquí que todo el mundo se va tras de él. En nada progresamos persiguiéndolo, sino que lo hicimos aún más famoso [...]. Y he aquí que los estudiantes tienen en la ciudad todas las cosas a mano, pero, despreciando todas las deli-

\footnotetext{
${ }^{6}$ Fulco de Deuil, Ep. XVI: Ad Abaelardum (ed. Cousin, 1849: 703-704): "Roma suos tibi docendos transmittebat alumnos: et quae olim omnium artium scientiam auditoribus solebat infundere, sapientioriem te se sapiente transmissis scolaribus monstrabat. [...] Anglorum turbam iuиenum mare interiacens et undarum procella terribilis non terrebat: sed omni periculo contempto, audito tuo nomine, ad te confluebat. Remota Brittania sua animalia erudienda destinabat. Andegauenses eorum edomita feritate tibi famulabantur in suis. [...] Teutonicus et Sueuius tuum calere ingenium, laudare et praedicare assidue studebat. Praetereo cunctos Parisiorum ciuitatem habitantes, et intra Galliarum proximas et remotissimas partes qui sic a te doceri sitiebant, ac si nihil disciplinae non apud te inueniri potuisset". Todas las traducciones son propias, salvo expresa indicación en contrario.
}

Stylos. 2021; 30 (30); pp. 255-272; ISSN: 0327-8859; E-ISSN: 2683-7900 
cias civiles, confluyen en las carencias de la soledad y se hacen míseros por su propia voluntad"".

Sin embargo, la comunidad colapsa en 1127, y Abelardo se lanza a nuevas desventuras que le permitirán volver a dar clases recién en 1133 y hasta poco antes de ser convocado a Sens para enfrentar su segundo concilio. Sería en el monte Santa Genoveva donde congregaría, por última vez, a decenas de admiradores que posiblemente ya habían perdido las esperanzas de poder escuchar sus lecciones. Entre todos ellos encontramos, por ejemplo, a un Juan de Salisbury apenas llegado de su Inglaterra natal. Su testimonio da cuenta de que, pese a todo, el prestigio del "peripatético Palatino, cuya teoría lógica lo eleva sobre todos sus coetáneos al punto que se lo considera como el único interlocutor válido de Aristóteles"8 permanecía incólume.

Ya hacia el final de su vida, cuando había atravesado todas las calamidades que la Fortuna le había deparado, Abelardo seguirá alimentando los cálamos de una generación. La Metamorfosis de Goliás, un poema goliardo anónimo que recorre tópicos usuales y nombres famosos de la escolástica del siglo XII, termina, precisamente, lamentando la segunda condena al Palatino. El desconocido poeta increpa a Bernardo por ser el mayor responsable, pero también al resto de los monjes que lo condenaron:

La esposa pregunta dónde está su Palatino, del que mana todo espíritu divino;

\footnotetext{
7 Pedro Abelardo, Historia calamitatum mearum X (ed. Luscombe, 2013: 84): “[...] tacite conquerentes et ingemiscentes dicebant: Ecce mundus totus post eum abiit, nichil persequendo profecimus, sed magis eum gloriosum effecimus. [...] Ecce in ciuitatibus omnia necessaria scolares ad manum habent, et ciuiles delitias contempnentes, ad solitudinis inopiam confluunt et sponte miseri fiunt". Trad. JAKUBECKI - BORELLI, 2021: 80.

${ }^{8}$ Juan de Salisbury, Metalogicon I.5 (ed. Hall - KeATs, 1991: 20): “Peripateticus Palatinus qui logicae opinionem praecipuit omnibus coaetaneis suis, adeo ut solus Aristotilis crederetur usus colloquio". El pasaje más citado al respecto es, sin embargo, el de II.10, donde Juan cuenta brevemente su propia experiencia como alumno de Abelardo. Un excelente trabajo histórico-biográfico en torno a este testimonio es el de LEJEUNE (2003).
}

Stylos. 2021; 30 (30); pp. 255-272; ISSN: 0327-8859; E-ISSN: 2683-7900 
La prole educada por el filósofo clama;

el encapuchado del pueblo, el primero de los encapuchados, envuelto cual cebolla en tres túnicas

hizo silenciar al gran maestro.

He aquí el rebaño de la perversidad, el rebaño de la perdición;

impío y deplorable heredero del Faraón,

dando la apariencia de religión,

aunque debajo se esconde un pequeño destello de superstición.<smiles>[AlH2]</smiles>

Que no quede sin efecto lo acordado

por la sanción de tan grande curia, que se dé por sentado;

y que el rebaño encapuchado sea insultado

y de las escuelas filosóficas, expulsado. ${ }^{9}$

Estrechamente vinculada a esta queja se encuentra la Apología de Berengario de Poitiers, quien, al igual que la mayoría de los autores del colectivo goliardo, es un joven estudiante citadino que se vale de la parodia y la sátira como herramientas de denuncia. Sin embargo, y diferencia de todos los testimonios que hemos considerado hasta aquí, el suyo tiene una particularidad que nos obliga a dedicarle mayor atención: no se trata de una evocación nostálgica de los hechos o de una crítica escrita con la serenidad que otorga la distancia temporal, sino que es un producto directo y contemporáneo a la tempestad desatada por el Concilio de Sens.

\footnotetext{
${ }^{9}$ Anónimo, Metamorfosis de Golias, (ed. Wright, 184: 29-30, vv. 54-56 y 59): “Nupta quarit ubi sit suus Palatinus / cujus totus extitit spiritus divinus [...] Clamant a philosopho proles educati, / cucullatus populi primas cucullati; / et ut cepe tunicis tribus tunicati, / imponi silentium fecit tanto vati. / Grex est hic nequitio, grex perditionis; / impius et pessimus hares Pharaonis, / speciem exterius dans religionis, / sed subest scintillula superstitionis. [...] / Quicquid tanta curia sanctione datur, Inon cedat in irritum, ratum habeatur; / cucullatus igitur grex vilipendatur, / et a philosophicis scolis expellatur". Trad. JAKUBECKI-LUDUEÑA para UNIPE, en prensa. Se debe advertir que Wright le adscribe la autoría a Walter de Map a este y muchos otros poemas de hoy se consideran apócrifos.
}

Stylos. 2021; 30 (30); pp. 255-272; ISSN: 0327-8859; E-ISSN: 2683-7900 


\section{BERENGARIO, EL DISCÍPULO INDIGNADO}

El título completo de la invectiva de Berengario es Apología de Berengario de Poitiers contra Bernardo, santo abad de Claraval y otros que condenaron a Pedro Abelardo. ${ }^{10} \mathrm{Su}$ tono a todas luces ofuscado y la nula mención de la muerte de Abelardo -que tuvo lugar menos de un año después de la condena de Inocencio II promovida por el abad cisterciense-, hacen pensar que fue escrita apenas transcurridos los acontecimientos en cuestión, esto es, después de julio de $1141 \mathrm{y}$ antes de abril de $1142 .{ }^{11}$

Lo poco que se conoce de este "excéntrico apólogo" proviene de sus escritos. ${ }^{12} \mathrm{El}$ dato biográfico que más nos interesa aquí es que fue alumno directo de Abelardo, a quien se refiere como "praeceptor meus". Más aún, muy probablemente lo haya sido en el mismo momento o apenas antes del Concilio, dado que, dice, "en ese entonces yo era adolescente, y la sombra del bozo aún no oscurecía mis inmaduras mejillas". ${ }^{13}$ Además, su destreza retórica y los conocimientos tanto de las artes del trivium como de los autores paganos -no menor, por cierto, al que poseía de los Padres de la Iglesiano dejan lugar a dudas sobre su paso por las escuelas citadinas. ${ }^{14}$ De hecho, él mismo se inserta explícitamente en ese ambiente cuando explica qué lo llevó a escribir el texto: “... como estudiante - dice- a menudo disfrutaba de-

${ }^{10}$ Apologia Berengarii Pictauensis contra sanctum Bernardum Claraeuallensem abbatem et alios qui condemnauerunt Petrum Abaelardum.

${ }^{11}$ Cf. Luscombe (1966: 322, n. 16; 1969: 32, n. 1). Retoma la idea Thomson (1980: 90). Para la cronología de los sucesos relativos a la condena consúltese Mews (2002: 381-382).

12 "bizarre apologist" en LusCOMBE (1966: 319; 1969: 29). Las obras de Berengario que han sido editadas y cuya atribución está confirmada son la Apologia, una epístola a los cartujos, y una epístola al obispo de Mende. Las tres fueron editadas por THOMSON (1980) y, sobre esta base, reeditadas en $F a A A$. Sin embargo, en este último se arriesga la hipótesis de que nos hayan llegado más textos suyos. Cf. THOMSON - WinTERBOTTOM (2020: xviii)

${ }^{13}$ Berengario de Poitiers, Ad ep. mim. 8 (ed. Thomson - Winterbottom, 2020: 67): "Damnauerat Abaelardum praeceptorem meum [...] Eram ea tempestate adulescens, nondumque impuberes malas nubes lanuginis adumbrabat [...]". Para el resto de los datos biográficos véase THOMSON - WiNTERBOTTOM (2020: xiv-Xv).

${ }^{14}$ Aunque SiKes (1965: 233), da por sentado que Berengario fue un monje, no hay suficientes datos para fundamentar esta presunción. Más aún, en la epístola al obispo de Mende habla de sí como un "secular". Cf. Berengario de Poitiers, Ad. ep. mim. 9 (ed. Thomson WinTERBOTTOM, 2020: 68). Cf. LuSCOMBE (1966: 320; 1969: 30).

Stylos. 2021; 30 (30); pp. 255-272; ISSN: 0327-8859; E-ISSN: 2683-7900 
clamar sobre un tema inventado. ${ }^{15}$ Luego, ante la favorable perspectiva de una contienda auténtica, me sentí movido a justificar a Abelardo y refutar la audacia del abad". ${ }^{16}$ De allí que la mayor parte del opúsculo o, si se quiere, esta declamación de la vida real, sea una embestida directa contra Bernardo, a quien el autor compara con un "sicario que sale de su escondite". ${ }^{17}$

Berengario, entonces, comienza su Apología expresando irónicamente su asombro por el hecho de que Bernardo, un "ignorante de las artes liberales", haya alcanzado tanto renombre ${ }^{18}$ y pasa a señalar algunos errores minucias, en realidad- encontrados en sus obras. Le recrimina, por ejemplo, que en sus Sermones sobre el Cantar de los cantares haya interpolado una oración fúnebre dedicada a su hermano, mezclando así los géneros líricos; convirtiendo, "de manera deplorable, cánticos en elegías, poemas en trenos". ${ }^{19}$ Esta especie de sacrilegio retórico es corregido de inmediato invocando el Ars poetica de Horacio y recomendándole al abad estudiar a los gentiles. Más adelante le critica la máxima expresada en De diligendo Deo, que sostiene que el modo de amar a Dios es amarlo sin modo (o medida). ${ }^{20}$ Le dice que por querer hacerse el retórico (rethoricari voluisti), prescribe una manera imposible de amar, una manera contradictoria que nadie versado

\footnotetext{
${ }^{15}$ La declamatio, precisamente, es un ejercicio propio de los estudiantes de retórica, que consistía en debates ficticios cuyo fin era practicar las reglas aprendidas. Cf. "declamatio" en MagnaVACCA (2014: 187-188).

${ }^{16}$ Berengario de Poitiers, Ad. ep. mim. 8 (ed. Thomson - Winterbottom, 2020: 67): “[...] eratque mihi uelut scholastico animus infleta crebro materia declamare. Porro ueri certaminis arridente uena, pectus appuli ut purgarem Abaelardum abbatisque confutarem audaciam".

${ }^{17}$ Berengario de Poitiers, Apologia 7 (ed. Thomson - Winterbottom, 2020: 42): "In uia Christi ambulantem tamquam sicarius de occulto prodiens tunica inconsutili spoliasti". Berengario dice esto en referencia a la epístola que Bernardo le envió al Papa Inocencio II mientras Abelardo se dirigía a Roma para replicar el veredicto del concilio.

${ }^{18}$ Berengario de Poitiers, Apologia 1 (ed. Thomson - WinterbotTom, 2020: 41): "Mirantur homines in te, liberalium disciplinarum ignaro, tantam ubertatem facundiae, quia emissiones tuae iam cooperuerunt uniuersam superficiem terrae".

${ }^{19}$ Berengario de Poitiers, Apologia 53 (ed. ThOMson - Winterbottom, 2020: 52): “Tu uero terminos transgrediens quos posuerunt patres tui cantica in elegos, carmina in threnos sorte miserabili conuertisti". Cf. Bernardo, Sermones in Cant. Cant. 26.2-13.

${ }^{20}$ Bernardo de Claraval, De diligendo Deo 1.1 (SBO 3: 119.19): "Causa diligendi Deum, Deus est; modus, sine modo diligere".
}

Stylos. 2021; 30 (30); pp. 255-272; ISSN: 0327-8859; E-ISSN: 2683-7900 
en dialéctica estaría dispuesto a tomar en serio. ${ }^{21} \mathrm{El}$ joven estudiante parece olvidar que Bernardo era un monje, y en todo caso un místico, no un dialéctico.

Pero solo parece, no lo olvida. En realidad, se trata de una estrategia retórica. Su intención al marcar estas torpezas es mostrar que Bernardo también se equivocó, que ni siquiera él, por muy santo que fuere, es infalible. Y lo revela diciendo: "Tú, ¿por qué erraste? O a sabiendas o por ignorancia. Si erraste a sabiendas, te reconoces enemigo de la Iglesia; si erraste por ignorancia, ¿cómo eres defensor de la Iglesia tú, que no sabes distinguir un error". ${ }^{22}$ Su maestro, Pedro, se había equivocado y Berengario no lo niega. Pero considera que Bernardo, justamente en virtud de sus propios errores, debería haber tenido mayor deferencia con el Magister a la hora de marcar sus desvíos doctrinales. El abad, en cambio, habría actuado a los ojos de Berengario con una severidad tal que incluso lleva a cuestionar sus motivos:

“Cómo te disponías a corregir a Pedro, si le quitabas el amor del pueblo? A partir de [tu] conducta se llega a la conclusión de que contra Pedro te inflamó no el amor de la corrección sino el deseo de la propia venganza [...] Allí donde falta misericordia no está la corrección del justo sino la confusa barbarie del tirano" -pues, agrega Berengario un poco más adelante- "no es asunto de la misericordia el aumentar la culpa, sino disminuirla". 23

\footnotetext{
${ }^{21}$ Cf. Berengario de Poitiers, Apologia 78-83 (ed. Thomson - Winterbottom, 2020: 58).

${ }^{22}$ Berengario de Poitiers, Apologia 43 (ed. ThOMSON - WinterbotTom, 2020: 50): "Tu quare errasti? Aut sciens aut nesciens errasti. Si sciens errasti, hostis Ecclesiae comprobaris; si nesciens errasti, quomodo es defensor Ecclesiae, qui errorem nescis discernere?". Para Thomson (2020: xvii), por el contrario, el propósito sería más bien el de mostrar que Bernardo es "in some senses a heretic".

${ }^{23}$ Berengario de Poitiers, Apologia 27 (ed. Thomson - Winterbottom, 2020: 47): "Sed corrigere, inquiunt fautores abbatis, Petrum uolebat. Si [...] Petro amorem populi tollebas, quomodo corrigere disponebas? Ex qua complexione in summam redigitur te in Petrum exarsisse non amore correctionis sed desiderio propriae ultionis? [...] Vbi enim deest misericordia, non est correctio iusti sed barbaries incondita tyranni"; Ibid. 84 (2020: 59): "Non est negotium misericordis culpam augere sed minuere".
}

Stylos. 2021; 30 (30); pp. 255-272; ISSN: 0327-8859; E-ISSN: 2683-7900 
El indignado discípulo, que oscila entre la ironía y el agravio, se muestra abiertamente desafiante en un pasaje que, de modo engañoso y tal vez deliberado, comienza como una modesta petición: "Permite, te ruego, que contigo Pedro sea cristiano. Y si quieres, contigo será católico. Y si no quieres, también será católico. Pues Dios es común, no privado". ${ }^{24}$ De este modo, Berengario pone de manifiesto que ni él ni Pedro reniegan de la fe o de la Iglesia, sino de Bernardo. Y para reforzar la imagen de su maestro como buen ortodoxo, nuestro apólogo adjunta la Confesión de fe a Eloísa, en la que Abelardo no solo sigue el símbolo de Atanasio, sino que se retracta con una fórmula hoy ya célebre: "no quiero ser filósofo si por ello me rebelo contra Pablo, no quiero ser Aristóteles si por ello me aparto de Cristo". ${ }^{25}$

Casi una década después, en una retractación -equívoca e insuficiente para algunos ${ }^{26}$ dirigida al obispo de Mende, Berengario dirá, refiriéndose a Bernardo: "si acaso dije algo contra la persona de ese hombre de Dios, debe leerse en broma, no en serio". ${ }^{27}$ Sin embargo, nada indica que así lo haya sido.

Ahora bien, decíamos al comienzo, que la Apologia contiene, además, una denuncia de las irregularidades y el abuso de poder que sufriera Abelardo en Sens por parte de los responsables de la condena. Berengario, pues, nos ofrece un recuento de los eventos que, aunque no se contradice, contrasta con los restantes testimonios que nos han llegado del Concilio, y cuyo detalle ha hecho pensar que estuvo presente y que, por tanto, no todo lo que dice es un mero producto de su furibunda imaginación. ${ }^{28}$ De hecho, algunos

\footnotetext{
${ }^{24}$ Berengario de Poitiers, Apologia 29 (ed. Thomson - Winterbottom, 2020: 48): "Patere, quaeso, Petrum tecum esse Christianum. Et si uis, tecum erit Catholicus. Et si non uis, tamen erit Catholicus. Communis enim Deus est, non priuatus".

${ }^{25}$ Pedro Abelardo, Conf. fid. ad Hel. (ed. BuRnetT, 1986: 152; en la Apologia, ed. Thomson WinTERBOTTOM, 2020: 48): “... nolo sic esse philosophus ut recalcitrem Paulo. Nolo sic esse Aristoteles ut secludar a Christo". Trad. JAKUBECKI-BORELLI (2021: 229). VAN DEN EYNDE (1962: 344-347) ha demostrado que la carta fue escrita efectivamente por Abelardo antes del juicio. Mews (1985: 132), por su parte, la ha datado en 1140.

${ }^{26}$ Cf. VACANDARD (1095: 721).

${ }^{27}$ Berengario de Poitiers, Ad. ep. mim. 16 (ed. Thomson - Winterbottom, 2020: 69): “[...] si quid in personam hominis Dei dixi, ioco legatur, non serio".

${ }^{28}$ El que sostiene explícitamente que pudo haber sido uno de los asistentes es LusCOMBE (1966: 323; 1969: 33). En cuanto a los restantes testimonios, puede compararse a Apologia,
}

Stylos. 2021; 30 (30); pp. 255-272; ISSN: 0327-8859; E-ISSN: 2683-7900 
especialistas han advertido que Juan de Salisbury reportó un procedimiento similar en el concilio de Reims de 1148, liderado también por Bernardo, esta vez contra Gilberto de la Porrée. ${ }^{29}$ Tal vez Berengario, empujado por la impotencia y la admiración por Abelardo, solo estaba exagerando. Sea de ello lo que fuere, lo cierto es que la narración no deja de ser, cuanto menos, curiosa. Sirva como muestra el siguiente pasaje, en el que convergen hechos conocidos con pormenores inauditos:

"Finalmente, después del almuerzo, el libro de Pedro fue llevado $<$ al recinto>, y se le ordenó a uno que leyera en voz alta y fuerte los opúsculos de Pedro. Pero aquel, movido por el odio a Pedro [...] habló más fuerte de lo que se le pidió. Poco después, hubieras visto a los prelados insultar, patalear, reír y bromear, al punto que cualquiera habría juzgado con facilidad que aquellos no estaban cumpliendo con sus votos a Cristo, sino a Baco [...] En fin, cuando sonaba algo sutil y divino -lo que resultaba insólito para los oídos de los prelados- a todos los oyentes se les rompía el corazón y rechinaban los dientes contra Pedro. [...] Mientras el lector grita, el auditorio, ronca. Uno se apoya con el codo para descansar la vista; otro, sobre una suave almohada, le da pelea al sueño con sus párpados, otro dormita reclinando la cabeza sobre sus rodillas. Así pues, cuando el lector encontraba algo suficientemente espinoso contra Pedro, alzaba la voz ante los sordos oídos de los prelados: 'lo condenan?' Entonces algunos, apenas despertándose por la última sílaba, con voz somnolienta y la cabeza gacha decían 'condenamos'. Otros, en cambio, excitados por la revuelta de las condenas, decapitada la primera sílaba '-namos', decían". ${ }^{30}$

v.g., con la breve crónica de secretario de Bernardo, Godofredo de Auxerre, en Vita prima III.13-14 ( $P L$ 185: 311-312), o una más imparcial, pero de segunda mano, la de Otto de Freising en su Gesta Friderici I. Imperatoris 1.49-50.

${ }^{29}$ Cf. Luscombe (1966: 324-325; 1969: 34-35); Mews (2002: 370).

${ }^{30}$ Berengario de Poitiers, Apologia 9-15 (ed. Thomson - Winterbottom, 2020: 42-44): “Denique post prandium allatus est liber Petri, et cuidam praeceptum est ut uoce clamosa Petri opuscula personaret. At ille et Petri odio animatus [...] sonorius quam postulatum fuerat exclamauit. Post aliqua pontifices insultare, pedem pedi applodere, ridere, nugari conspiceres, ut facile quilibet iudicaret illos non Christo uota persoluere sed Baccho [...] Denique cum

Stylos. 2021; 30 (30); pp. 255-272; ISSN: 0327-8859; E-ISSN: 2683-7900 
Berengario finaliza la narración haciendo gala una vez más de su buen manejo de las artes del lenguaje, por una parte, y de su erudición cristiana, por otra. Unas pocas palabras -algunas provenientes de las Escrituras- le bastan para componer una imagen de un fuerte contraste: "Haciendo, hicieron, y desenvainaron viperinas lenguas contra Abelardo; tergiversaron lo tergiversado, y tragaron vino como quien a un pobre devora a escondidas. En medio de todo esto, Pedro oraba". ${ }^{31}$

El joven alumno, incapaz de refrenar la ferocidad de su pluma, llama a los jueces, "ciegos" -más de una vez-, "sacerdotes de Baco", "vejadores de la inocencia", "animales" y más específicamente, "cerdas obesas" (así, en femenino). ${ }^{32}$ Sea por devoción al maestro o por justa indignación -o por ambas-, lo cierto es que llega incluso a comparar la tribulación de Abelardo con el martirio de Cristo, y la "implacable" actitud de los obispos con las de los sacerdotes y fariseos que conspiraron contra Jesús al ver que sus milagros convocaban cada vez más adeptos. El pasaje, de hecho, es una parodia de un episodio del evangelio de Juan. ${ }^{33}$

El ímpetu que condujo a Berengario a denunciar lo que siempre consideró un abuso de autoridad por parte de la Iglesia, es el mismo que lo llevó a prometer que iba a justificar él mismo los pretendidos errores que le habían imputado a Pedro. Sin embargo, no ha pasado de ser una promesa. Como le

aliquid subtile diuinumque sonabat, quod auribus pontificalibus erat insolitum, audientes omnes dissecabantur cordibus suis et stridebant dentibus in Petru. [...] Inter haec sonat lector, stertit auditor. Alius cubito innititur ut det oculis suis somnum; alius super molle ceruical dormitionem palpebris suis molitur; alius super genua sua caput reclinans dormitat. Cum itaque lector in Petri satis aliquod reperiret spinetum, surdis exclamabat auribus pontificum: 'damnatis?' Tunc quidam uix ad extremam syllabam expergefacti, somnolenta uoce, capite pendulo 'damnamus' aiebant. Alii uero damnantium tumultu excitati, decapitata prima syllaba, 'namus' inquiunt".

${ }^{31}$ Berengario de Poitiers, Apologia 18 (ed. Thomson - Winterbottom, 2020: 45): "Facientes fecistis, et linguas uipereas in Abaelardum euaginastis. Subuersi subuertistis, et uinum absorbuistis sicut qui deuorat pauperem in abscondito. Inter haec Petrus orabat". Cf. "facientes fecistis", Jer. 22: 4, 44: 17; “sicut... abscondito", Hab. 3: 14.

${ }^{32}$ Cf. Berengario de Poitiers, Apologia 12, 15, 16 y 21 (ed. Thomson - Winterbottom, 2020: 43-46): "caeci", "sacerdotes (sacerdotibus) Bacchi", "innocentiae uexatores", "animales" y "sues crassae".

${ }^{33}$ Cf. Berengario de Poitiers, Apologia 17 (ed. Thomson - Winterbottom, 2020: 45) y Jn. 11: $47-53$.

Stylos. 2021; 30 (30); pp. 255-272; ISSN: 0327-8859; E-ISSN: 2683-7900 
explicará luego al obispo de Mende, con el tiempo fue cambiando su parecer respecto de la doctrina del Magister, al que de todos modos se las ingenia para seguir protegiendo. Dice, en efecto: "No quise ser el abogado de las tesis objetadas a Abelardo porque incluso si tenían buen sabor, no sonaban bien". ${ }^{34}$

Como es de imaginar, la Apología rápidamente circuló por toda Francia y, al parecer, llegó hasta Italia ${ }^{35}$ El torrente de ofensas que Berengario había proferido contra el santo abad de Claraval y la curia suscitó tanta hostilidad contra él que debió marcharse a otras tierras. ${ }^{36}$ De hecho, es por eso que se retracta con el obispo, el "buen pastor": para que haga que por su intercesión dejen de balar las ovejas, pues Berengario, dice refiriéndose a sí mismo, es el perro que las cuida, no el lobo que las acecha. ${ }^{37}$

Con todo, nuestro autor, aún si crecido y arrepentido, no perderá las mañas. Mantiene firme su convicción de que el proceso fue formalmente injusto pues se hizo in absentia y a partir de un texto leído de manera superficial. A sus ojos, Bernardo seguirá siendo aquel que "había condenado a Abelardo, y estrangulado su voz sin haberla escuchado". ${ }^{38}$ De ahí que cierre su carta - y con ella se despida también de la causa-, con un ambiguo pedido de

\footnotetext{
${ }^{34}$ Berengario de Poitiers, Ad. ep. mim. 15 (ed. Thomson - Winterbottom, 2020: 69): “Nolui esse patronus capitulorum obiectorum Abaelardo, quia, etsi sanum saperent, non sane sonabant".

${ }^{35}$ Berengario de Poitiers, Ad. ep. mim. 16 (ed. Thomson - Winterbottom, 2020: 69): "Fecissem hoc, inquam, nisi cassa esset industria. Remanerent enim uiua exemplaria, quae iam per totam Franciam et Italiam cucurrerunt". Esta afirmación tiene asidero en la evidencia material que poseemos. Actualmente conservarmos seis testigos de la Apologia; uno de ellos (París, BnF, lat. 2923), incluso, fue glosado por Francisco Petrarca, a quien perteneció. Cf. THOMSON - WINTERBOTTOM (2020: xxvi-xxxi).

${ }^{36}$ Cf. Berengario de Poitiers, Ad. ep. mim. 1-2 y 26 (ed. ThOMSON - WinTERBOTTOM interbottom, 2020: 66 y 71) Seguimos aquí la interpretación de VACANDARD (1905: 721). A los enemigos ganados por la Apologia se le suman los hermanos cartujos, contra quienes también escribió una invectiva quejándose de minucias.

${ }^{37}$ Cf. Berengario de Poitiers, Ad. ep. mim. 2 (ed. ThOMSON - WinterbotTom, 2020: 66).

${ }^{38}$ Berengario de Poitiers, Ad. ep. mim. 8 (ed. Thomson - Winterbottom, 2020: 67) "Damnauerat, inquam, Abaelardum, et uocem eius sine audientia strangulauerat".
}

Stylos. 2021; 30 (30); pp. 255-272; ISSN: 0327-8859; E-ISSN: 2683-7900 
disculpas: "Te ruego el perdón como inocente y, si te gusta más, te lo pido como culpable". ${ }^{39}$

\section{CONSIDERACIONES FINALES}

Es difícil "concluir" cuando no se trata de un trabajo tético, aunque nada nos impide ensayar algunas reflexiones finales. Y para ello voy a retomar la conclusión a la que llegó Vacandard, el encargado de escribir la entrada de Berengario en el Dictionaire de théologie catholique allá por el 1905. A sus ojos, la Apología no es más que un "violent pamphlet sans valeur histori$q u e "{ }^{40}$ Sin embargo, si a nadie se le ocurriría poner en cuestión el interés de los testimonios que compartí en la primera parte de este artículo, me pregunto por qué la invectiva de Berengario sería una excepción. Esta "exasperada defensa", así como la epístola al obispo merecen, al menos, un detallado estudio literario. Coincido con Rémusat cuando afirma que, detrás de las muchas puerilidades y chicanas groseras desperdigadas por el texto, es posible encontrar un verdadero ingenio satírico, un espíritu libre y una argumentación elocuente destinada a un público instruido. ${ }^{41}$

Pero, además, considero que también poseen valor histórico. ${ }^{42}$ Aun cuando los errores señalados a Bernardo sean triviales y la narración del Concilio no ayude a esclarecer los eventos, ella no deja de ser fructuosa para la historia de la filosofía en la medida en que, siendo producto de una reacción directa y no solo un relato retrospectivo, muestra mejor que cualquier otro testimonio "the pain felt by the disciples of Abelard at the persecutions directed against a master whom they dearly loved", ${ }^{43}$ así como la animad-

\footnotetext{
${ }^{39}$ Berengario de Poitiers, Ad. ep. mim. 25 (ed. Thomson - Winterbottom, 2020: 71): "Veniam rogo innocens, et, si magis placet, ueniam postulo reus".

${ }^{40}$ Cf. VACANDARD (1095: 720). Este autor no ha sido el único en pensar así. Aunque desactualizadas, sirvan al menos como ejemplo las referencias reunidas por LusCOMBE (1966: 321, n. 10/ 1969: 31, n. 1).

${ }^{41}$ Cf. RÉmuSAT (1845: 234).

42 En esto coincido con las observaciones de GiLSON (1940: 167) y LuSCOMBE. (1966: 321, 335 / 1969: 31, 47)

${ }^{43}$ GiLson, (1940: 167)
}

Stylos. 2021; 30 (30); pp. 255-272; ISSN: 0327-8859; E-ISSN: 2683-7900 
versión que ello causó contra Bernardo; la misma que se refleja en los versos finales de la Metamorfosis de Goliás. Más aún, si tomamos en cuenta no solo el amor de sus defensores sino también el encono que -según Berengariosentían por él sus detractores, podemos hablar directamente de las pasiones que suscitó el maestro palatino en su generación. Generación fascinada, para bien o para mal, por una doctrina que, incluso si no fue retomada de manera explícita, dejó huellas precisas en el pensamiento de quienes fueran sus alumnos, como Juan de Salisbury, Roberto de Melún, Arnaldo de Brescia y el que, a su vez, se convertirá en "el maestro de sentencias", Pedro Lombardo.

\section{REFERENCIAS BIBLIOGRÁFICAS}

\section{FUENTES}

AA.VV., The Latin Poems Commonly Attributed to Walter Mapes, WRIGHT, TH. (ed.), Londres: Camden Society, 1841.

BERENGAR OF POITIERS, Apologia contra sanctum Bernardum et alios. Epistola contra cartusienses. Epistola ad episcopum mimatensem, 111138. En ThOMSON, R., "The Satirical Works of Berengar of Poitiers: An Edition with Introduction", Mediaeval Studies 1980 42: 89-138.

BERENGAR OF POITIERS, Apology in defence of Peter Abelard. Against the Carthusians. To the Bishop of Mende, 41-71. En THOMSON, R. Y WinTERBOTTOM, M. (eds.), For and Against Abelard. The Invective of Bernard of Clairvaux and Berengar of Poitiers, Woodbridge: The Boydell Press, 2020.

Bernardus Claraeuallensis, Liber de diligendo Deo, LeClerCQ, J., TALBOt, C. y RochaIs, H., Tractatus et Opucula, Turnhout: Brepols, 2017 (SBO 3).

IOANNES SARESBERIENSIS, Metalogicon, HaLl, J. B. (ED.), KeATS-RoHAN, K. (aux.), Turnhout: Brepols, 1991 (CCCM 98).

Pedro Abelardo et al., Cartas de Abelardo y Eloísa, JAKUBECKI, N. Y Borelli, M. (trads.), Madrid: Punto de Vista Editores, 2021.

Stylos. 2021; 30 (30); pp. 255-272; ISSN: 0327-8859; E-ISSN: 2683-7900 
Peter Abelard, Confessio fidei ad Heloisam, 152-153. En Burnett, Ch., “Confessio fidei ad Heloisam'. Abelard's last letter to Heloise?", Mittellateinisch Jahrbuch 1986 21: 147-155.

Peter ABELARD, The Letter Collection of Peter Abelard and Heloise, LusCOMBE, D. (ed.), Oxford: Clarendon Press, 2013.

PIERRE AbÉlARD, Petri Abaelardi opera, Cousin, V. (ed.), Jourdain, C. Y DESPOIS, E. (aux.), París: E. Typis C. Lahure et Sociorum, 1849, v. I.

\section{ESTUDIOS BIBLIOGRÁFICOS CITADOS}

GILSON, E., "Berenger the Scholastic", appendix III: 167-169. En Ibid., The Mystical Theology of St Bernard, Nueva York: Sheed and Ward, 1940.

LEJEUne, F., "Pierre Abélard et Jean de Salisbury: Metalogicon II, 10", 6375. En Jolivet, J. y Habrias, H. (dirs.), Pierre Abélard. Colloque international de Nantes, Rennes: Presses Universitaires de Rennes, 2003.

LusCOMBE, D., "Berengar, Defender of Peter Abelard", Recherches de Théologie ancienne et médiévale 1966 33: 319-337.

Luscombe, D., The School of Peter Abelard, Cambridge: Cambridge University Press, 1969.

MagnavacCA, S., Léxico técnico de Filosofía Medieval, Buenos Aires: Miño y Dávila, 2014.

Mews, C., "On Dating the Works of Peter Abelard", Archives d'histoire doctrinale et littéraire du Moyen Âge 1985 52: 73-134.

MEws, C., "The Council of Sens (1141): Abelard, Bernard, and the Fear of Social Upheaval", Speculum 2002 77(2): 342-382.

PERNOUD, R., Eloísa y Abelardo, Barcelona: El Acantilado, 2011.

RASHDall, H., The Universities of Europe in the Middle Ages, Oxford: Clarendon Press, 1895.

RÉMUSAT, Ch., Abélard, París: Ladrange, 1845, t. I.

SIKES, M., Peter Abailard, Nueva York: Russell and Russell, 1965.

THOMson, R., "The Satirical Works of Berengar of Poitiers: An Edition with Introduction", Mediaeval Studies 1980 42: 89-138.

Stylos. 2021; 30 (30); pp. 255-272; ISSN: 0327-8859; E-ISSN: 2683-7900 
VACANDARD, E., "Bérenger de Poitiers", cols. 720-722. En Mangenot, E. (dir.), Dictionnaire de théologie catholique, París: Letouzey et Ané, 1905 , t. II.

VAN DEN EYNDE, D., "Chronologie des écrits d'Abelard à Heloïse", Antonianum 1962 37: pp. 337-349.

Stylos. 2021; 30 (30); pp. 255-272; ISSN: 0327-8859; E-ISSN: 2683-7900 